\title{
Green economy as a vector of building and development of smart cities
}

\author{
Valery Anufriev ${ }^{1 \mathrm{a}}$, Elena Anufrieva ${ }^{1}$, Lidia Petrunko $^{2}$, and Aytkali Kaminov ${ }^{1}$ \\ ${ }^{1}$ Ural Federal University, Higher School of Economy and Management, 620002, Yekaterinburg, \\ Russia \\ ${ }^{2}$ Ural Centre for Energy Efficiency and Environment, 620049, Yekaterinburg, Russia
}

\begin{abstract}
The vector of smart city development is power-efficient and low-carbon policy (strategy) within the framework of the green economy. Sustainable development and green growth of cities can be provided by active growth of the human capital owing to creative, innovative ideas, approaches and solutions. Idea creators should be prepared in the best green gymnasiums, universities, academies. Energy saving and energy efficiency, besides creation of conditions required for innovations in the main parts of economy, will considerably reduce the risks of climate change and natural and man-made disasters related to it. It will introduce considerable additional contribution into the development of smart cities.
\end{abstract}

\section{Introduction}

More than $74 \%$ of the Russian population live in cities today. In this connection the sustainable development of Russian economy greatly depends on the level of city development and the quality of the human capital of urban population [1]. The modern city does not result only from its architecture and infrastructure. Thus the anthropogenic load on the planet due to the impact of the modern resource economy has brought about considerable overshoot in adaptation potentials of nature and contributes into the climate change. Nowadays the world economy consumes by one and a half more natural resources than the planet can reproduce. The situation is aggravated by the increase in the amount of domestic and industry wastes. The Russian economy is much more power-consuming than that of developed countries. And all of this is intensified by the influence of natural and manmade disasters related to emissions of greenhouse gases from burning hydrocarbon fuels, from landfill $\mathrm{CH}_{4}$.

There is no alternative to transition to the green economy. More than 150 countries have changed or are changing over to the low-carbon economies. According to [2] in the beginning of 2015 "at least 164 countries had renewable energy targets, and an estimated 145 countries had renewable energy support policies in place".

One of the main trends of the green economy is its energy efficiency that has great difficulties in building into the economies of Russia, the Republic of Kazakhstan, Ukraine and some others post-Soviet states.

\footnotetext{
${ }^{\text {a }}$ Corresponding author: v.p.anufriev@urfu.ru
} 


\section{Smart city}

A smart city needs smart decisions, that lead to a new level of development. A smart city also needs innovation techniques providing economical and ecological utilization of the city infrastructure, which creates the modern level of life quality. "Smart city means smart management, smart habitation, smart people, smart environment, smart economy, smart transport" [3]. The conception of smart cities is being implemented actively, for example in Songdo City, South Korea. Construction of new smart cities is planned in China and India, the USA and the United Kingdom, Spain and Brazil. In Moscow's Expo Center there is a smart city prototype [4].

In our opinion "smart" city is a city where power-efficient and low-carbon technologies are used at both industrial enterprises and urban systems of life activity. It is the city that is served by green energy (by sources of renewable energy - the sun, wind, water, thermal pumps etc.) and green transport (electric vehicles, public transport facilities (better railtracked ones)), with maximum quantity of green zones. In smart cities traffic jams are struggled not only at the expense of multilevel garages, but by commissioning safe walking tracks and bikeways, then the most part of citizens would use bikes making better their health as well as the environment of the city. It is easy to determine how much any city is polluted, it is enough to look at the verdure in it. The exhausts of cars and industrial enterprises creates coating on plants and they die slowly. Verdure is the best detector of the ecological situation in cities. It is motor cars and industrial enterprises in cities that impacts the environment considerably.

It is impossible to create a smart city by the efforts of ordinary citizens only. More often it is the initiative of government or local authorities. Is it possible to change to sustainable green city development without the purposeful national green policy and economy? The answer that is staring us in the face is no. The experience of smart cities in Sweden, Canada etc. shows that all the necessary services for citizens should be in the area of 10-15 minute walk [5]. According to the strategic development plan "Vision 2030" the main targets for further improvement of the city were established: power effective transport, use of environmentally friendly construction materials, use of clean energy, rational use of the ground and water, waste processing with minimum influence on environment, etc. In addition to it in Stockholm the program on greenhouse gases emission reduction and climate change is realized [6].

And all this can be achieved only by careful planning of urban environment and considered introduction of green technologies.

\section{Human capital}

In a smart city (country) smart and industrious people live, they are able to study under anybody and to accept any help, talented people are the most valuable property in a state where the government is honest and competent and it is able to plan, to pose large-scale economic tasks for a long period of time and correct them depending on the situation, play an important role in investment attraction and innovation implementation [7].

It is such kind of people that can be attributed not to human factor but to human capital which will be effective in both exploitation of disappearing natural recourses and utilization of swiftly increasing space, industrial, and domestic wastes.

Smart people, probably, should live in smart houses. What is a smart house? It is a power-efficient house, with least emissions of greenhouse gases and pollutants, their roofs are decorated with a green loan or flower garden. It turns out that soil on a roof is excellent heat insulator, and that loft is the most energy wasteful premise. Elements of public infrastructure are controlled remotely though computer or mobile phone, that is at 
a distance of thousand kilometers the houseowner can adjust the temperature and humidity of air in the apartment, control over its security and air it as required.

Authors consider green technologies as innovations not only in technology but in law, insurance, taxes and other fields. The innovations promote green (smart) economy, the matrix of all the innovations. To create the possibility for such transition a new kind of specialists is required. Specialists in green economy and smart citizens should be educated in smart universities, that is green universities. We have already had such universities in Russia, MSU, MGIMO and others are among them. In Ekaterinburg such title can be given to UrFU, as well as USMU, USFEU, USUAA, USAU.

For that continuous teaching green economy is required from a green gymnasium (kindergarten) to a green academy created on the basis of several green universities, with training courses on green economy given by teachers of the universities who specialize in a certain discipline, that considerably increases the course rating. It can be the second diploma within the framework of distant education on Sustainable Development and Green Growth offered by universities of BRICS countries. One of the main tasks of the universities is to give their graduates wide world view and to teach them thinking constructively, as well as to find talented specialists.

Behind every idea and innovative decision there is an individual (or a group), the idea creator. Naturally in the absence of such people the ideas providing the continuity of opportunity growth and the continuity of development are lacking. But history shows that the people were, are and will be. Exactly the people with their theoretic investigation and scientific and technical developments create prerequisites for choice of ways for further continuous development of society. Therefore the question is how to reproduce and form people who are able to generate and implement the ideas of continuous society development.

Creativity in economy is any process of search and implementation of solutions to complex tangled problems. The process of search and implementation of solutions to various economic, energy, climate, financial, social, legal, political and other problems is a creative one [8].

\section{Green economy}

Green economy (by authors' definition) is a system of economy management when economic growth is achieved owing to rational use of energy and natural resources, concomitant reduction of emissions of greenhouse gases and pollutants, as well as increase of the human capital significance (knowledge, creativity, culture).

The transition to the smart green economy takes place because the growing human capital, using their creative ideas and such scientific directions as neuroeconomics ${ }^{b}$, will help to induce innovative power efficient low-carbon, and nature protective green technologies. The green technologies will provide the economic green growth in the main areas of economy and will give the following additional results:

- prevented environmental damage owing to reduction of pollutants,

- reduced damage from climatic changes and reduced risk of natural and manmade disasters owing to decreasing emissions of greenhouse gases.

We overlooked the moment when such terms as smart networks, smart houses and cities came into wide use, but our great compatriot academician V.I. Vernadsky anticipated

\footnotetext{
b Neuroeconomics is an interdisciplinary scientific direction on the border between psychology, neurobiology and economics theory. It deals with the study of the decision making process while choosing alternatives, distributing risks and remuneration. To study human brain the science uses economic models, and to create the economic models it uses the achievements of neurobiology.
} 
the noosphere (the sphere of intellect) coming, when the thoughts, plans and business become reasonable. And we can suppose that power efficient low-carbon green economy is a predecessor of the noosphere economy $[9,10]$.

Green economy is the economy of the future because of its innovative character $(40 \%$ of all innovations are implemented within its framework). Green economy is an antirecessionary economy, for example, South Korea accepted the idea of the economy as the national idea during the crisis of 2009 and become one of the first countries emerging from it [11]. And because of the abovementioned factors green economy has no alternatives.

The situation with fuel and energy balance of the countries changes very quickly at the expense of renewables and other types of green power. So, according to the International Energy Agency [12] the share of use of renewables in the world will increase from $22 \%$ in 2013 to $26 \%$ in 2020 .

These years development of such branches as coal - and petrochemistry is planned. At the same time apart from use of coal as a fuel such innovative technologies as combustion of low-grade coals in the pseudo-liquefied layer, receiving of liquid fuel and synthetic gas from coal will find application.

Efficient energy consumption results not only in the consumption reduction but in the reduction of pollutants and emissions of greenhouse gases and therefore to reduction of the influence on climate changes: natural and manmade disasters, the damage of which is increasing annually.

Natural and manmade disasters and cataclysms increasing in frequency recently are related to the global climate changes in many respects. Retreat of the permafrost accompanied by worming in the northern regions of the country results in destruction of oil and gas pipelines, piled house footing, and manmade disasters. For example CEO UNILIVER official stated that the company loses about $\$ 330$ million per year because of natural cataclysms due to climate changes [13].

Climate changes, and global warming in particular, depend on the increase of GHG emissions into the Earth's atmosphere (the main of them is $\mathrm{CO}_{2}$ ). The gases are the result of hydrocarbon fossil fuel (coal, oil) burning. One of the key issues of the modern world economy is reduction of consumption of oil and coal as a fuel and transition to powerefficient and low carbon green power engineering an economy.

\section{Greenhouse emission in Sverdlovskaya Oblast}

In Russia the transition to power-efficient low-carbon development began in the first half of 1990s and moves forward with great difficulties. Universally recognized indicator of the power-efficiency is the amount of greenhouse emissions. Figure 1 shows the results of inspection of greenhouse gases in Sverdlovskaya Oblast, the forecast was made up to 2020 .

The data obtained show that the emission of greenhouse gases in Sverdlovskaya Oblast from 2017 to 2018 does not fit the parameters marked by the President of the Russian Federation. It means that the energy-consuming enterprises of the region should quickly develop a program on reduction of greenhouse gases, coordinated with the regional energy saving program taking into account the level of greenhouse gases reduction declared at the Climate Summit in Paris as $75-70 \%$ of 1990. 


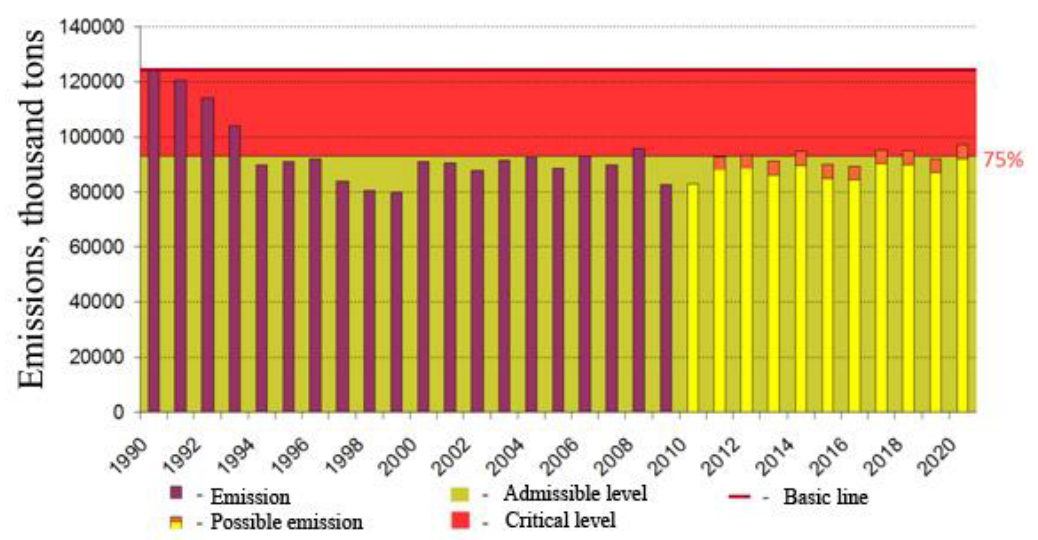

Fig. 1. Emissions of greenhouse gases coordinated with the level of the RF obligations up to 2020.

Taking into account the positive trend in greenhouse gas emissions approximately by $0.67 \%$ per year and the dynamics of Sverdlovskaya Oblast economic development, it creates prerequisites for further intense growth of greenhouse gases emissions. In the nearest perspective for 2017-2020 we exceed the level stated by the President by 5-9\%.

Figure 1 shows that in 2017 and 2018 the anticipated increase will be about $2 \%$, and by 2020 the emissions of greenhouse gases can exceed the level of obligations accepted in Sverdlovskaya Oblast by $4-5 \%$ [14].

Analysis showed the decrease of emissions of greenhouse gases is the responsibility of the sphere of electric energy production (decrease of specific fuel consumption per unit of supplied electricity) and metallurgy (increase of power efficiency).

Nowadays the problems with emission of greenhouse gases are not taken seriously by the government, science, business and citizens, though the fulfillment by enterprises in Sverdlovskaya Oblast requires the development of low carbon strategy in the region.

\section{Conclusion}

The scheme of transition to a new model of green economy is presented in the article as well as its acceleration by activation the creative and intellectual potential of human. It will allow the decrease of impact of pollutants and greenhouse gases, climate change, as well as the risks of natural and manmade disasters rise and decrease their consequences (Figure 2).

The problem of global climate change should be considered fully because global climate change, natural and manmade disasters are closely related to energy, economic, climate, and environmental problems in the "nature-society-human" system. Not only scientists and officials but ordinary people should understand them and be closely familiar with them. With that end in view the scheme should involve human capital that is able to start lowcarbon power-effective mechanism in maim sectors of Russian economy. The idea itself and transition from resource to green economy is a large-scale innovation covering all the sectors of the economy, and it begins from energy efficiency. 


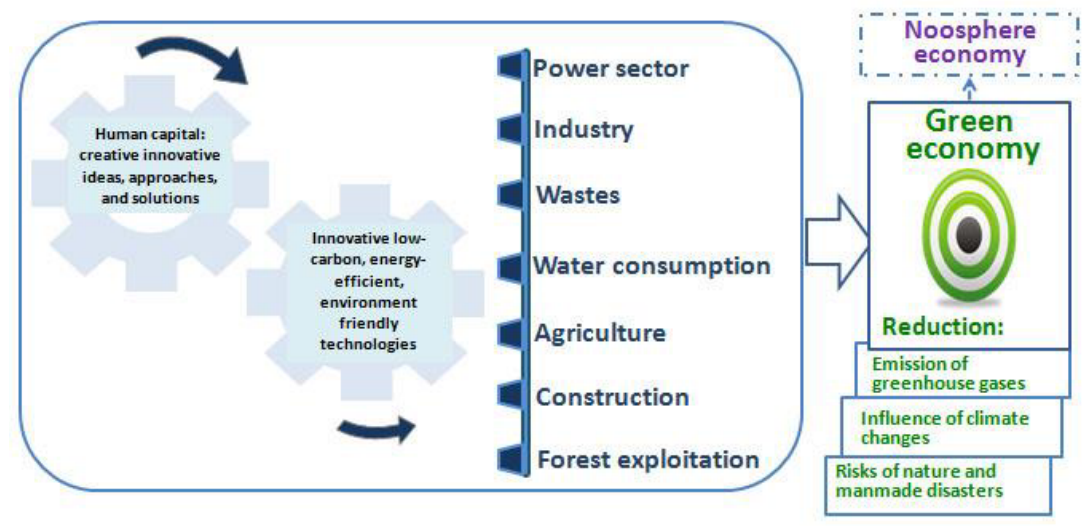

Fig. 2. Scheme of initiation of the transition to green (smart) economy model.

Figure 3 shows the total economic effect of:

-reducing consumption of fuel-energy resources;

-prevented environmental damage by reducing the amounts of pollutants and energy resources consumption;

-reducing the carbon footprint by decreasing emission of $\mathrm{CO}_{2}$-equivalent;

-reducing the risk of natural and manmade disasters due to reducing emissions of greenhouse gases.

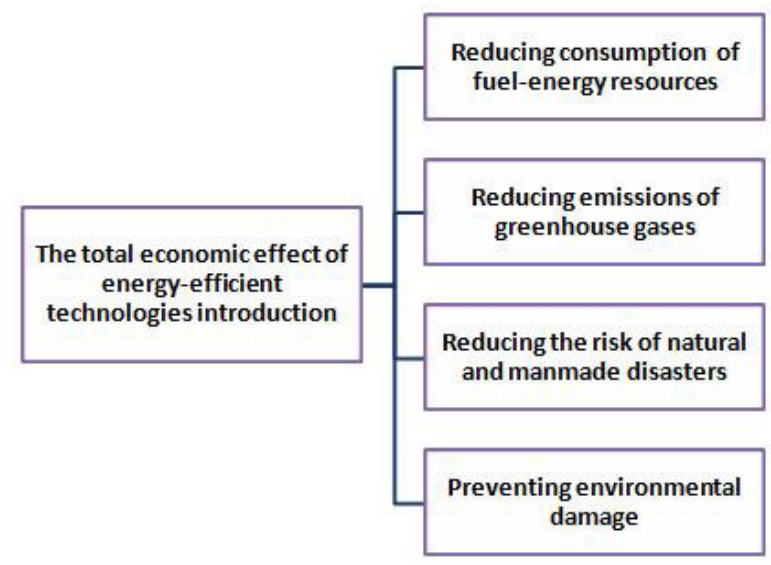

Fig. 3. Total economic effect of introduction of innovative power-efficient low-carbon technologies.

That is innovative solutions of energy saving and low-carbon strategy is the key trends of the Russian economy for a long period of time.

\section{References}

1. Russian population: size, dynamics, statistics, http://www.statdata.ru/russia

2. Renewables 2015 - Global Status Report, http://www.ren21.net/wpcontent/uploads/2015/07/REN12-GSR2015 Onlinebook low1.pdf

3. F.F. Kurbanova, I.M. Bilalova, Information package of the VIII International Student

Electronic Scientific Conference "Student Scientific Forum" (2016) 
4. In Moscow's Expo Center a prototype of "a smart city" was built, http://expert.ru/2015/11/12/v-moskovskom-ekspotsentre-postroili-prototip-umnogo-goroda 5. City of Vancouver: the official website of Vancouver City Administration, http://vancouver.ca/green-vancouver/targets-and-priority-actions.aspx

6. ECO2 Cities: Ecological Cities as Economic Cities, http://www.esmap.org/sites/esmap.org/files/CS Stockholm.pdf

7. Li Kuan Yu, The history of Singapore. From «the third world» to the first one» (2005)

8. O.L. Kuznetsov, P.G. Kuznetsov, B.E. Bol'shakov, The system nature- societypeople: sustainable development (Dubna, 2000)

9. V.I. Vernadskiy, Biosphere and Noosphere (2004)

10. A.I. Bedriy. Creative economy, 5 (77), 16-21 (2013)

11. How to guide: Low-emission Development Strategies and Nationally Appropriate Mitigation Actions: Eastern Europe and CIS. http://www.undp.org/content/dam/undp/library/Environment $\% 20$ and $\% 20$ Energy/Climate $\%$ 20Change/Mitigation/Low-

emission $\% 20$ Development $\% 20$ Strategies $\% 20$ and $\% 20$ Nationallv $\% 20$ Appropriate $\% 20 \mathrm{Mitig}$ ation $\% 20$

12. Renewable energy. Medium-term market report 2015. Executive summary. https://www.iea.org/Textbase/npsum/MTrenew2015sum.pdf

13. Climate changes - business won't find it funny. http://www.rusecoiinion.ru/business140316

14. V.P. Anufriev, S.A. Yazykov, A.A. Panchenko, The Materials of the $5^{\text {th }}$ International Theoretical and Practical Conference "Efficient and Quality Electric Energy Supply and Utilization" (Ekaterinburg, 2016) 